\title{
BUSCANDO UMA CHANCE PARA O FILHO VIR A SER: A EXPERIÊNCIA DO PAI NA UTI ${ }^{1}$
}

\section{SEARCHING A CHANCE FOR THE CHILD TO BECOME: THE EXPERIENCE OF THE FATHER IN THE INTENSIVE CARE UNIT}

\author{
Aspásia Basile Gesteira Souza* \\ Margareth Angelo**
}

SOUZA. A.B.G.; ANGELO, M. Buscando uma chance para o filho vir a ser: a experiência do pai na unidade de Terapia Intensiva. Rev.Esc.Enf.USP, v.33, n.3, p. 255-64, set. 1999.

\begin{abstract}
RDSUMO
O presente estudo objetiva desvelar a experiência do pai cujo filho encontra-se em Unidcde de Terapia Intensiva Pediátrica, utilizando a pesquisa qualitativa, sob a perspectiva fenomenológica de Martin Heidegger, para analisar os discursos obtidos por entrevistas. Esta análise permitiu identificar três temas que configuraram aquela vivência em: Transformando seu medo em esperança, Percebendo-se como tomador de decisões e Agindo em benefício do filho. Estes temas desocultaram o fenômeno BUSCANDO UMA CHANCE PARA O FILHO VIR A SER, revelando que, para isso, o pai expõe o filho aos riscos e tratamentos que forem necessários, indicando que suas ações e a constante superação de seus sentimentos objetivam oferecer ao filho uma oportunidade para viver com plenitude.
\end{abstract}

UNITERMOS: Unidades de Terapia Intensiva Pediátrica. Relacões pai-filho.

\begin{abstract}
This study was intended to analyse the experience of the father who have a child in an Intensive Care Unit. by applyng the qualitative research under the phenomenologycal perspective of Martin Heidegger, it was to identify three themes which figured that experience:Transforming the fear into hope,Perceiving himself as the person who decides and Acting for his child benefit. These themes unveiled the phenomenon SEARCHING A CHANCE FOR THE CHILD TO BECOME, who reveals that submits his child to risks and to essential treatments while continuously unchanging overcomes his own feelings in order to offer to his child an opportunity of full living.
\end{abstract}

UNITERMS: Intensive Care Units, pediatric. Father-child relations.

\section{INTRODUÇÃO}

Ao fazer uma retrospectiva de minha trajetoria desde a graduação, recordo alguns momentos que pontuaram este caminhar onde meu foco de atenção se diversificou à medida em que situava meu ser enfermeira.

Primeiramente, meu vivenciar em Unidade de Terapia Intensiva (UTI) de adultos foi direcionado a doentes e doenças, delimitando meu cuidar ao paciente. Lembro hoje que sua família era, para mim, uma figura distante, sendo meu contato com esta formal e impessoal.

Tencionando aprimorar meus conhecimentos em Pediatria, cursei Especialização em Enfermagem Pediatrica, onde pela primeira vez sentia, na presença da família, uma constante. Foi então que, através da criança descobri a família, basicamente representada pela mãe.

Motivada por novas percepções do cuidar, onde

\footnotetext{
1 Resumo de Dissertaça de Mestrado, apresentado à Escola de Enfermagem da Universidade de São Paulo(EEUSP)

* Enfermeira, Profa. Adjunta da Universidade Cidade de São Paulo, disciplina de Semiologia, Especialista em Enfermagem Pediátrica, pela EPM; Mestre em Enfermagem Pediátrica, pela EEUSP.

* Enfermeira, professora doutora do depto. de Enfermagem Materno-infantil da EEUSP; Livre-Docente pela EEUSP,orientadora desta dissertaça.
} 
a família se mostrava presente, decidi por cursar mestrado em Enfermagem Pediátrica, o que proporcionou-me real oportunidade para refletir sobre o tema até então obscuro para mim: assistência de enfermagem à família.

Meu vivenciar profissional se solidificava em UTIP (Unidade de Terapia Intensiva Pediátrica) e meu cuidar comecava a se direcionar ao acompanhante que permanecia junto d̀ criança, já que existia na instituição em que trabalhava a internação conjunta. Pude perceber a presença mais constante da mãe, a preferência para que essa acompanhasse ao filho, entre outros.

Em uma determinada ocasião, duas crianças tiveram o pai como acompanhante em substituição à mãe.

Foi nessa situação, então, que pucle sentir a presença do pai junto a seu filho na UTI: o olhar carinhoso enquanto o filho dormia, a hábil troca de fraldas, a recreação oferecida incessantemente à criança, o apoio com palavras de encorajamento durante procedimentos invasivos. De alguma forma, essa convivência proporcionou-me envolvimento com o binômio pai-filho, levando-me a um novo perceber.

Assim desta experiência tão gratificante, surgiu minha inquietação em querer conhecer como o pai estava vivenciando aquela situação, como se situava naquele contexto, despertando-me para este estudo.

A maternidade e a paternidade estão cercadas de mitos, cristalizados e internalizados em relação aos binômios mãeffilho/ pai-filho, como a desvinculação do homem no processo de gerar ao filho e 0 amor incondicional da mãe, sendo, portanto vistas de forma dicotomizada e muitas vezes clistantes, podendo afetar, inclusive, a maneira de interagir com o filho doente.

No levantamento bibliográfico inicial, pude observar que a relação mãe-filho sempre foi objeto de estudo para muitas áreas do conhecimento. Alguns autores destacam esta relação valorizando a figura materna e referindo-se ao pai como figura coadjuvante descle a concepção até após o nascimento (BACH, 1983; CAVALCANTI, 1977; FIGUEIRA, 1981; SILVA, 1994; THIS, 1987). F I G U E I R A (1981) também afirma que o laço emocional mais forte entre duas pessoas é o de mãe e filho.

Os meios de comunicação em massa e a própria tradição popular fortalecem o conceito destas imagens, reforçando o papel da mãe junto ao filho em todos os momentos de sua vida.

BACH (1983) destaca o mito do amor da mãe como sendo natural e do pai como uma conquista do convívio, atribuindo ainda ao homem os papeis de autoridade e repressão. Assim, assumindo esta condição, o pai afasta-se dos filhos física e emocionalmente como que entendendo que as relações de amor são incompatíveis com o exercício do poder, como justifica SILVA (1994).

Incorporando papéis, reproduzindo e reforçando mitos dos quais não se conhece a origem, encontramos no final do século este modelo de pai agonizando.

Frequentemente, a propria mídia divulga as mais diversas tentativas do pai na aproximação de seus filhos, como solicitando a sua guarda em situações de separação, a figura do "pai solteiro", entre outros, favorecendo um novo pensar sobre esses conceitos. O pai cada vez mais percebe que seu amor é importante para os filhos, que não se substitui este amor e que sua ausência deixa a descoberto um espaço efetivo que o amor materno não irá preencher.

Assim, um homem-pai questionando-se sobre sua essência, seu existir, surge a procura de uma nova identidade.

Diante dessas questões, o que significaria para o casal, surpeendido pela doença, ter o filho internado na UTIP? Como este fato seria incorporado pelos pais? Como se daria esta experiência? Surge aí mais um foco de atenção para vários pesquisadores: BELLI (1992); BOUSSO (1992); FISER (1984); ROTHSTEIN (1980).

Ter o filho internado em UTIP como problema a ser investigado, tende naturalmente a envolver novamente o binômio mãe-filho pois, como aponta SILVA (1994), grande importância se dá à mãe e suas relações com a criança como feitos de saúde ou doença, de felicidade ou infelicidade.

Acredito que a mãe que vivencia esta situação experimenta profundo sofrimento e que a preocupação de vários pesquisadores direciona-se à sua compreensão. Mas como entendemos o pai que vivencia esta realidade?

A saúde ou doença de um membro afeta o restante da família, como confirmam CHAVES; FABER (1987), o que reforça o desejo de aproximarme da experiência do pai naquela situação, já que também estaria "afetado" pela doença do filho assim como a mãe.

Não é minha intenção fustigar a existência de uma quantidade ou qualidade de vivências e sentimentos maiores ou menores entre mãe e pai, mas creio que o seu significado é importante para ambos e que a experiência do pai também deva ser sendo conhecida.

Assim, à partir de minha vivência profissional e do levantamento bibliográfico, suscitou-me interesse em conhecer a experiência do universo masculino. Consequentemente minha trajetoria neste trabalho está voltada para a compreensão da experiência do pai com filho internado em UTIP. 


\section{TRAJETÓRIA METODOLÓGICA}

$\mathrm{Na}$ busca do conhecimento, a ciência utilizouse por séculos, do método experimental objetivo como único meio para encontrar respostas confiáveis aos seus questionamentos.

Contestando essa forma de conhecer, surge a fenomenologia, descrita por Edmund Husserl (18591938) na Alemanha, como alternativa na busca do conhecimento, considerando o método experimental pouco adequado para o trato das questões do homem e de seu mundo vivido.

FORGHIERI (1993) atenta que Husserl tenta construir uma ciência dirigida para desvelar as experências vividas. Aparece desta forma a proposta de mostrar o fenômeno ao invés de demonstrá-lo.

Buscando compreender o fenômeno na reflexão a partir do retorno já vivido, surge a possibilidade de olhar as coisas como elas se manifestam a partir da descrição dos atos da consciência, procurando seu significado para o sujeito que se expressa através do discurso (linguagem, gestos, silêncio, fisionomia).

Visando chegar a essa essência intuitiva do fenômeno o pesquisador procede a redução fenomenologica, constituída basicamente por dois momentos, segundo FORGHIERI (1993) :a) isolando o fenômeno, separando essência da realidade empírica; b) distanciamento e reflexão sobre o próprio fenômeno, descrevendo o seu significado.

Pela redução fenomenológica pratica-se a Epoché que é a suspensão de qualquer julgamento, colocando-se a realidade concebida (crenças, proposiçōes) entre parênteses.

Tendo em vista que a abordagem fenomenologica visa compreender o existencial, buscando valorizar o conteúdo da experiência em si mesma vejo, nesse método, a possibilidade de ir ao encontro do fenomeno. A fenomenologia contribui para a compreensão do ser humano, alvo do cuidar da enfermagem, e é nessa abordagem compreensiva que ocorre um chamamento à reflexão que neste estudo se volta ao ser-pai que vivencia a experiência de ter o filho da UTIP.

\subsection{A abordagem fenomenológica de Martin Heidegger}

Este pensador alemão, assistente e sucessor de Husserl, apresentado por MARTINS (1983) como o fenomenólogo existencial mais independente, subsistente, firme e sólido pensador da condição do ser humano do mundo contemporâneo, busca na fenomenologia tratar o fenômeno na sua essência , nele mesmo, ou seja proporcionar "a volta às coisas mesmas".
HEIDEGGER (1989) redefine a fenomenologia, caracterizando-a como método que não procura o quê do objeto, mas o como: como se mostra a partir de si próprio, como experencia o mundo.

Ao ente humano Heidegger denomina Ser-aí (ou Dasein) que resulta da condição de abertura para a experiência, fazendo surgir o Ser-aí-no-mundo ou um Ser-existindo-aí, interagindo com as coisas, com os outros, com o mundo, de diversas maneiras, da forma que lhe for possível.

O Ser-aí-no-mundo relaciona-se com este em três níveis: a) o ambiente, ou o mundo ao redor (Umwelt); b) as relações, ou o mundo com os semelhantes (Mitwelt); c) o interior, ou o mundo consigo mesmo (Eigenwelt), que dão forma à existência do homem.

Para Heidegger o Ser-no-mundo é afetado pela facticidade e pela temporalidade. Facticidade, como própria condição humana, onde o homem encontrase comprometido com situações que não escolheu e temporalidade como existir no passado, presente e futuro.

A partir da fenomenologia heideggeriana, de ver o homem através dele próprio, busco compreender àquele ser que adentra com o filho em uma UTI e se vê obrigado a refazer o seu Aí-nomundo-com, sem aviso prévio, muitas vezes sem ajuda e sem compreensão e é nesse "sem" que minha preocupação se dirige, à partir da fenomenologia, na tentativa de desvelar esta experiência vivenciada pelo ser pai.

\subsection{A pesquisa}

\subsubsection{A região de inquérito}

O estudo do fenômeno demandou a busca de um contexto onde pudesse ser inquerido. Com este propósito foi escolhido, então, uma UTIP clínica, especializada em cardiopatias congênitas, de um hospital público, na cidade de São Paulo, que atende crianças entre 0 e 12 anos, dispondo de seis leitos.

A escolha do local deu-se por, principalmente, permitir alojamento conjunto e visitação diária em dois períodos, o que facilitaria o contato com os sujeitos deste estudo, sendo também meu campo de atuação.

Foram constituídos, como sujeitos do estudo, homens que experenciavam a situação de Ser-pai de uma criança internada naquela UTI e que concordassem em participar da pesquisa. Não determinei qualquer outro requisito.

O número de pais considerados como sujeitos da pesquisa foi definido pelas expressões dos próprios discursos, isto é, enquanto foram surgindo dados de 
interesse para elucidar o fenômeno, obtidos principalmente pela convergência nas falas. Participaram desta pesquisa nove indivíduos caracterizados pela conscientização de ser-pai com o filho na UTIP.

\subsubsection{A aproximação ao ser pai}

Ap6s um primeiro ou segundo contato, apresentava-me como autora deste estudo, solicitando espaço para conversarmos sobre isto. Em sala reservada, garantindo a privacidade dos sujeitos, expunha minha vontade em ouvir sua experiência naquela situação e esclarecia-os sobre a forma como os dados seriam coletados, garantindolhes o anonimato, bem como da possibilidade do uso de gravador durante a entrevista e necessidade de agendamento de um outro momento para nosso encontro.

A maioria das entrevistas deu-se no horário de visitas subseqüente, já que estariam visitando ou acompanhando ao filho.

\subsubsection{A coleta dos depoimentos}

Os dados foram coletados através de entrevista individual, considerada como recurso mais adequado para aproximar-me do fenômeno.

Para CARVALHO (1991), a entrevista, sob a otica fenomenológica, tem a intenção de ver e observar o sujeito a partir deste, ou seja, captar a sua subjetividade, apresentando-se como uma técnica de esclarecimento e apoio próxima à perspectiva compreensiva, que se refere à vivências e sentidos.

Desta forma, a entrevista sem questões diretivas ou estruturadas se apresenta como a mais adequada. Para nortear a coleta de dados, busquei um fio condutor para a entrevista sob a forma de questão orientadora, explicitada na frase: "O que é, para o senhor, ter seu filho internado na UTI?", sendo que freqüentemente substituía a palavra filho pelo nome da criança, forma mais proxima e familiar ao sujeito pai.

Ao iniciar a entrevista, o indivíduo era identificado pelo primeiro nome, por um número em ordem crescente e pelo nome do filho. Os dados foram coletados entre os meses de Janeiro e Abril de 1996.

Conforme os discursos foram sendo obtidos, prosseguia à transcrição dos mesmos, na íntegra, buscando manter a sua fala originária. A partir dos relatos obtidos, "mergulhava" nos discursos a fim de captar seus significados.

\subsubsection{A interpretação dos depoimentos}

Os procedimentos de análise dos dados tiveram como objetivo captar os significados para o pai sobre o vivenciar a experiência de ter o filho internado na UTIP. As Unidades de Significado (U.S.) são as descrições que se interrelacionam e que nos mostram fatos e sentimentos identificados pelo sujeito como focos de sua atenção.

Tendo as falas originárias dos sujeitos já transcritas, utilizei o modelo sugerido por GOMES (1992) e FORGHIERI (1993) para proceder sua análise, como segue: leitura de cada relato, na íntegra; releitura atenta, voltada para cada parte do relato; envolvimento com a experiência, praticando a Epoché em busca das U.S.; reflexão e interpretação compreensiva dos dados. Assim, tornou-se possível enunciar os significados e sua articulação nos discursos. As frases que possibilitassem captar o significado daquela vivência eram transcritas de forma a representá-las, como exemplifico:

\begin{tabular}{|l|l|}
\hline \multicolumn{1}{|c|}{ Relato do pai } & \multicolumn{1}{|c|}{ U.S. identificada } \\
\hline $\begin{array}{l}\text { "O que eu sinto é que eu fico muito angustiado por } \\
\text { ele tá aqui." (P5) }\end{array}$ & Sentindo angústia pela internação do filho na UTI \\
\hline $\begin{array}{l}\text { "Ela é muito frágil também qualquer coisinha ela tá } \\
\text { chorando." (P7) }\end{array}$ & Percebendo a esposa como um ser frágil \\
\hline
\end{tabular}

Com as U.S. de cada discurso, procurei as convergências entre elas, agrupando-as de modo que expressassem os momentos daquela vivência mostrando o intencional da consciência, de forma que pudesse extrair o sentido comum entre eles, originando os significados ampliados:

\begin{tabular}{|l|l|}
\hline \multicolumn{1}{|c|}{ Unidade de significado } & \multicolumn{1}{|c|}{ Significado ampliado } \\
\hline Preocupando-se se o filho vai morrer (P1) & Sente medo de perder o filho \\
\cline { 1 - 1 } Tendo medo da filha não resistir (P2) & \\
\hline
\end{tabular}


Os agrupamentos desses significados possibilitaram a reflexão sobre as experiências relatadas, sendo reunidas em sub-temas. Os subtemas expressam os componentes em comum, dandome maior entendimento dos significados encontrados e, ao serem organizados segundo estes, formaram os temas deste estudo, ponto inicial para o desvelamento do fenômeno.

\section{APRESENTAÇÃO DOS RESULTADOS}

Os sub-temas possibilitaram a aproximação da vivência do pai e, ao serem analisadas, convergiram para três unidades temáticas dando forma à interpretação sobre aquela experiência.

Os temas que identifiquei, como a "moldura" do fenômeno, foram assim nomeados:

1.Transformando seu medo em esperança

2. Percebendo-se como tomador de decisões

3. Agindo em benefício do filho
Para facilitar a compreensão de cada tema, estes são apresentados em quadros, com os respectivos sub-temas e agrupamentos. Segue-se a cada um o texto explicativo onde exponho meu pensar, intencionando desvelar a experiência.

\subsection{Tema 1: Transformando seu medo em esperança}

O pai encontra-se em meio a sentimentos conflitantes, levando-o a experimentar, ao mesmo tempo, dor pelo que percebe da situação e esperança num futuro onde a busca da recuperação do filho norteia suas ações. Isso envolve medo e sofrimento que são condicionados, porém, à realidade e à evolução clínica do filho, pois percebe que a piora do estado clínico condiciona e direciona seu sofrimento.

Desta forma, tendo consciência de seu medo, procura em si mesmo elementos transformadores em algo em que possa se apoiar: sua esperança.

Esta vivência pode ser melhor compreendida no desdobramento dos sub-temas e significados ampliados, abaixo relacionados:

Quadro 1- Representação do tema Transformando seu medo em esperança

\begin{tabular}{|c|c|}
\hline Sub-temas & Significado ampliado \\
\hline $\begin{array}{l}\text { Percebendo a internação do filho } \\
\text { como momento de crise em sua } \\
\text { vida }\end{array}$ & $\begin{array}{l}\text { - ter o filho na UTI é uma desgraça } \\
\text { - sente angústia e preocupação } \\
\text { - percebe a internação como situação difícil de enfrentar }\end{array}$ \\
\hline $\begin{array}{l}\text { - Sofrendo com o sofrimento do } \\
\text { filho }\end{array}$ & $\begin{array}{l}\text { - sofre ao ver o filho chorar } \\
\text { - aflige-se ao ver que o filho tem suas atividades limitadas } \\
\text { - percebe os problemas do filho como sendo os seus } \\
\text { - sofre por ver o filho sedado } \\
\text { - deseja estar no lugar do filho }\end{array}$ \\
\hline $\begin{array}{l}\text { - Sofrendo com a possibilidade do } \\
\text { filho morrer }\end{array}$ & $\begin{array}{l}\text { - sente medo de perder o filho } \\
\text { - percebe a morte do filho como uma dor inimaginável }\end{array}$ \\
\hline $\begin{array}{l}\text { - Sentindo preocupação } \\
\text { condicionada à evolução do filho }\end{array}$ & $\begin{array}{l}\text { - sentirá preocupação se a evolução da doença for desfavorável } \\
\text { - quer conhecer a evolução do filho como estratégia para controlar sua } \\
\text { preocupação } \\
\text { - acredita que seu desespero aumentará se o filho tiver piora do quadro }\end{array}$ \\
\hline - Confiando em Deus & - tem fé em Deus \\
\hline $\begin{array}{l}\text { - Acredita na chance de } \\
\text { recuperação do filho }\end{array}$ & $\begin{array}{l}\text { - não sente medo da cirurgia } \\
\text { - percebe que o hospital tem experiência no tratamento } \\
\text { acredita que o filho sairá de alta hospitalar } \\
\text { - mantém pensamento positivo } \\
\text { - sente esperança quanto a recuperação do filho } \\
\text { - acredita que o filho vencerá novamente a doença }\end{array}$ \\
\hline
\end{tabular}


O lidar com a internação do filho na UTIP, leva o pai a experenciar sofrimento, tristeza e medo ao deparar-se com esta facticidade que envolve a extensão de seu ser: o filho tão dependente de um pai que não sabe se conseguirá enfrentar aquele momento. Enfrentar esta situação coloca em jogo suas emoções e sentimentos que se confrontam com a postura que assume na família e sociedade e, neste turbilhar, pretende dar continuidade ao seu ser-nomundo, tentando conciliar o que sente com o que pensa e com o que tem de fazer.

A mudança em sua vida, advinda da internação do filho cardiopata na UTI, é percebida como crise cuja resolução poderá apresentar-se positivamente, com enfrentamento e crescimento pessoal ou deterioramento do comportamento representado por condutas depressivas, de apatia, agressividade e ansiedade, demonstrados no angustiado depoimento:

"Esqueço de comer, não tenho cabeça prá nada! Eu sonho, às vezes eu levanto, sento na cama dormindo. A minha mulher fala para mim que eu levanto dormindo, pensando e falando sobre a nenê que tá doente Tô sofrendo muito, muito sofrimento." (P9)

O sofrimento se faz presente nos momentos onde presencia o filho sofrer. A preocupação com o real parece ser a base deste vivenciar, onde o pai precisa certificar-se do que acontece com o filho na UTI e dar vasão a seu medo, ao invés de se envolver num sofrimento díspare com a realidade. Isso não significa dizer, já que tratamos de diversos seres-aí, que o sofrer, o chorar, não estejam presentes fora do ambiente hospitalar, mas a necessidade de estar em sintonia com os fatos estão presentes na forma com que os sujeitos reagem.

Estas percepções vem revestidas de impotência, que lhe causa culpa por sentir que não está cumprindo seu papel de protetor e defensor do filho, daí surgindo o desejo de transferência, de tomar para si a facticidade que o filho vive, como identificado nestas falas:

\section{"Se carrego ele para um hospital, um centro-cirúrgico, UTI, eu também tenho problema." (P6) \\ "Queria que eu morresse primeiro que ela, ela me enterrar e não eu enterrar ela." (P9)}

A morte é vista como uma possibilidade bastante próxima na U'TI, e o pai sente medo de perder o filho amado. Ao se ver frente a possibilidade da morte do filho, depara-se com a finitude de sua propria existência e ao perceber o filho como continuidade de seu próprio existir, se vê duplamente ameaçado pela morte, por isso, percebe: a morte como dor inimaginável, como verbaliza na frase:

"Ah! ̀̀ uma dor forte, né? Uma coisa assim que você não imagina." (P7)

Quando refere esta dor como inimaginável, o pai está querendo situar esta dor como sendo sua, sendo impossível para alguém saber o que ele vivenciaria.

O pai teme a morte do filho e vive um luto fora do tempo, um ser-sem antes de estar concretizado. Organiza e reorganiza um viver-com e um viver-sem, num movimento pendular entre a doença congênita agravada e uma proximidade da finitude do filho com a desejada evolução favorável do quadro.

O medo e a preocupação estão presentes, porém são condicionados à evolução do quadro clínico, reforçando a idéia de que o sofrimento existe, mas não é fundado em expectativas e sim em fatos diretamente relacionados com a melhora ou piora do filho, por isso quer conhecer a evolução da criança como estratégia para controlar sua preocupação, como evidencia a fala:

"Eu gostaria de saber o que realmente pode acontecer. É que eu mesmo já comeco a me preparar para o que possa acontecer." (P6)

Este contexto também denota a importância do real para o pai. Esta experiência faz emergir a necessidade de apegar-se em algo além de si, para reforçar-se enquanto humano e, de alguma forma, reafirmar a possibilidade de enfrentar aquele momento, acreditando na ajuda além da competência da equipe, além dos cuidados e da terapêutica.

Em geral, o sofrimento aproxima o homem de Deus e da religiosidade, e é nessa crença que o pai se procura, enquanto Extensão Divina. Como criatura diante do Criador, coloca-se na posição de entregar, em confiança, o destino de seu filho a um Ser Superior, não vendo melhor escolha do que esta para depositar seu sofrimento. "A gente deixa ele na mão de Deus." (P8)

Crer em Deus também significa ter possibilidades, acreditar num vir-a-ser do filho e com-o-filho, revelando, neste trabalho, o ponto inicial da transformação de medos em esperança. Dando forma a este tema a crença na chance de recuperação do filho se mostra como o extremo desta trajetoria iniciada com medo e sofrimento e se transmutando em confiança e esperança.

O pai se tranquiliza também ao acreditar na cirurgia e na competência do hospital especializado, 
dando-lhe a sensação de que está fazendo a escolha certa, mantendo o pensamento positivo como estratégia para se fortalecer e acreditar que o filho sairá de alta hospitalar. Esta crença circunscrita esse vivenciar, pois o pai tem, nesta esperança, a motivação necessária para suplantar seus temores, superar sua crise e transformá-los em confiança num vir-a-ser com o filho.

\subsection{Tema 2: Percebendo-se como tomador de decisões}

Ao tentar aproximar-me do fenômeno, objeto deste estudo, deparei-me com Unidades de Significado que refletiam o papel do homem na sociedade, como o de detentor do poder e provedor da família.
Essa faceta do fenômeno desmembra-se nos subtemas apresentados a seguir, que melhor explicitam aquela experiência onde o pai, coloca-se no centro da situação onde a doença do filho resultou em internação na UTI e se mobiliza para decidir. Decidir também significa agir e é neste movimento de ação, de até transformar seu medo em esperança como discutido no tema anterior, que parece repousar a vivência do pai nessa experiência. Colocando-se, ou sendo colocado, ao centro dessa roda-viva, o pai vive esta importante face do fenômeno, onde dependem e emergem dele as decisões.

Quadro 2 - Representação do tema Percebendo-se como tomador de decisões

\begin{tabular}{|c|c|}
\hline Sub-temas & Significado ampliado \\
\hline $\begin{array}{l}\text { - Percebendo-se como apoio para a } \\
\text { esposa }\end{array}$ & $\begin{array}{l}\text { - preocupa-se se a esposa suportará ao fato do filho vir a morrer } \\
\text { - preocupa-se por não poder ficar com a esposa no hospital } \\
\text { - fica preocupado com a esposa vivenciando a internação do filho } \\
\text { - percebe a esposa como um ser frágil } \\
\text { - acredita que a esposa não tem condições de enfrentar a internação do } \\
\text { filho }\end{array}$ \\
\hline $\begin{array}{l}\text { - Tendo que dar continuidade ao } \\
\text { papel de provedor }\end{array}$ & $\begin{array}{l}\text { - tendo que se ausentar do hospital para garantir o sustento familiar } \\
\text { - trabalha pensando no filho e esposa } \\
\text { que estão na UTI }\end{array}$ \\
\hline $\begin{array}{l}\text { - Preocupando-se por não saber o } \\
\text { que vai acontecer }\end{array}$ & $\begin{array}{l}\text { - fica preocupado quando não recebe informações } \\
\text { - sente necessidade de saber da evolução clínica do filho } \\
\text { - percebe que a equipe não se reporta a ele quanto a condutas } \\
\text { assumidas com o filho }\end{array}$ \\
\hline $\begin{array}{l}\text { - Percebendo que não pode hesitar } \\
\text { em suas decisões }\end{array}$ & $\begin{array}{l}\text { - não tendo dúvida quanto a concordar com o tratamento cirúrgico } \\
\text { - percebe urgência em suas decisões } \\
\text { - acredita poder interferir no processo de cura }\end{array}$ \\
\hline
\end{tabular}

Surge no homem outro foco de atenção: a preocupação com a mãe de seu filho. Esta preocupação abrange vários aspectos, pois o homem acredita que a esposa não tem condições de enfrentar a internação do filho, é carente de apoio e conforto, sentido-se responsável direto pelo atendimento dessas necessidades.

O homem percebe a esposa como um ser frágil, pois mostra seus sentimentos, exteriorizando-os principalmente através do choro, o que é intexpretado pelo homem como demonstração de fraqueza, como desoculta este discurso:

"Tô aqui e vou para casa, fica ela (a esposa) aqui com ele, né? É a única coisa que eu fico preocupado. É que ela é muito frágil também, qualquer coisinha ela tá chorando" (P7)
Sentindo-se protetor da esposa, neste momento em que ambos necessitam de proteção e carinho, o pai assume o papel de apoiador e de um ser-aí onde a facticidade de ter o filho na UTI o faz sentir responsável em apoiar a mãe de seu filho.

Além disso o papel de provedor da família surge como o dever, incorporado nas relações familiares e sociais, de providenciar o sustento do clã, suprindo suas necessidades básicas, o que é encarado como obrigação, não se permitindo falhar neste ponto. O pai teme que o vínculo empregatício seja abalado por faltas, atrasos e licenças, e vê na continuação de suas atividades a segurança financeira que precisa proporcionar à família.

Desta forma, o pai trabalha pensando no filho e esposa que estão na UTI, exigindo de si o compartilhar sentimentos ambíguos e intensos, mas tentando conciliar essa vivência com seu cotidiano. 
Seguindo sua trajetória nessa experiência, o pai depara-se com as incertezas do futuro. Sendo ele um decisor, sente-se angustiado por não dominar os fatos que estão por vir.

Ter as coisas sob controle configura esta faceta do fenômeno, por isso, o pai fica preocupado quando não recebe informações, principal instrumento que viabiliza suas ações. Estar informado significa ter suporte para nortear suas atitudes.

Dentro desse contexto, emerge seu papel enquanto responsável pela criança, nem sempre solicitado a opinar, causando-lhe estranheza o fato de não receber satisfações a respeito do que é feito com o seu filho, como salienta este pai:

"Até agora ninguém chegou e disse quais são os procedimentos se continuar com o problema: olha, o problema tá assim, pode acarretar isso, pode nos levar a fazer isso, isso." (P6)

A informação é vista como um direito seu, enquanto pai, e um dever da equipe, que está lidando com seu filho. Desta maneira, ao diminuir suas incertezas pela obtenção de informações, o pai sentese menos ansioso, podendo então controlar a situação e continuar a tomar decisões.

$\mathrm{Na}$ incumbência de decidir, o pai nota que não pode hesitar e percebe urgência em suas decisões, já que se convence que, dependendo do que fizer, coloca em risco o sucesso do tratamento e o bem. estar da família.

Estar em prontidão indica estar pronto para agir, e o pai se coloca mais uma vez no movimento da ação, acreditando poder interferir no processo de cura, decidindo os destinos do filho, como desvela este trecho:

"Não sei como vai ser e a preocupação é um pouco maior, mas se eu não faço a cirurgia e se fecha o canal ela pode falecer também. Não tenho escolha." (P2)

Agir sem hesitação leva o sujeito a apresentarse como super-humano, com potencialidade capaz de contemplar, de todos os ângulos, os papéis que exigem dele alguma atuação, fazendo emergir um ser-pai decisor.

\subsection{Tema 3: Agindo em benefício do filho}

A experiência do pai que vivencia a internação do filho na UTI também é representada como a intenção dos sujeitos em mobilizarem-se à favor do filho. Este tema desenvolve-se nos sub-temas emergidos dos agrupamentos das Unidades de Significados.

Quadro 3 - Representação do tema Agindo em benefício do filho

\begin{tabular}{|l|l|}
\hline \multicolumn{1}{|c|}{ Sub-temas } & \multicolumn{1}{c|}{ Significado ampliado } \\
\hline $\begin{array}{l}\text { - Concretizando seu amor pelo } \\
\text { filho }\end{array}$ & $\begin{array}{l}\text { - acredita que o filho é o maior bem que possa ter } \\
\text { - sente amor pelo filho }\end{array}$ \\
\hline $\begin{array}{l}\text { - Acreditando que a U'TI e equipe } \\
\text { representam chance de recupe- } \\
\text { ração para o filho }\end{array}$ & $\begin{array}{l}\text { - acredita que na UTI o filho será bem cuidado } \\
\text { - percebe a UTI como um recurso no tratamento do filho } \\
\text { - confia na equipe da UTI }\end{array}$ \\
\hline $\begin{array}{l}\text { - Buscando o tratamento que o } \\
\text { filho precisa }\end{array}$ & $\begin{array}{l}\text { - sente preocupação quanto ao tratamento adotado } \\
\text { - reconhece os riscos da cirurgia } \\
\text { - expõe o filho aos tratamentos disponíveis }\end{array}$ \\
\hline
\end{tabular}

Ao confrontar-se com aquela situação, o pai percebe o quão valiosa é aquela criança para si e acredita que o filho é o maior bem que possa ter, tornando-o consciente de um sentimento de amor e apêgo que talvez não tenha sido à prova anteriormente. Tomar consciência do quanto e do como ama ao filho é assim clarificado por este pai:

"Ter um filho é a coisa mais rica que você tem, uma coisa que você adora. Ai todo mundo sente, né? Quando principalmente num estado grave." ( $P 7)$

Ao agirem a favor do filho, os sujeitos experimentam uma nova forma de perceber a Unidade de Terapia Intensiva. As idéias de que na
UTI estão internadas crianças gravemente atingidas pela doença, irrecuperáveis ou sem prognóstico, confrontam-se com um novo pensar onde aquela unidade assume posição estratégica na recuperação e reversão dos quadros mais severos de descompensação ou risco de vida, fazendo surgir o conceito de local onde a vida é preservada.

Ao assim enxergar àquele centro, o pai acredita que na UTI o filho será bem cuidado e percebe a UTI como um recurso a mais no tratamento do filho, como nos explicitam estes depoimentos:

"Mas agora que ele tá aqui é bom, ele tá nas mãos de vocês que vão cuidar dele. 
Agora tô mais calmo porque ele tá na UTI e vai ser olhado." (P1)

"Aqui eu sei que tá na UTI porque tá o tratamento mais intensivo, direto com ele." (P5)

Demonstrando a intenção do pai em procurar toda a espécie de tratamento, clínico ou cirúrgico, para o filho, surge este sub-tema que revela a procura da melhor opção, até encontrar o que julga mais adequado, fazendo-o sentir como coresponsável por aquele tratamento. Esse movimento de sair em busca é exemplificado por este pai:

"Eu sou de 600Km daqui, no interior,né? Desde que nasceu há três anos... a cidade é fraca em medicina. Ai eu fui correndo para um lugar mais próximo, mais próximo, até cair dentro de Marília, que tem um grande centro de cardiologia." (P6

Buscando o tratamento para oferecer ao filho a chance de ser uma criança como as outras representa, pois, o objetivo destas ações e, para alcançá-lo, o pai acredita que deve submetê-lo ao que for necessario e expõe o filho aos tratamentos disponíveis, na tentativa de obter a cura que devolverá a ele o estado de saúde compatível com a qualidade de vida que espera para o filho, como clarifica este pai:

('espera) "Que opera ele e ele seja um menino como os outros, como eu, normal."(P8)

\section{COMPREENDENDO O FENÔMENO}

Ao realizar este estudo tentei ir ao encontro do mundo vivido daquele pai que experenciava ter seu filho internado na UTIP. Foi surpreendente para mim deparar-me com o ser-homem, tentando superar sua fragilidade e medo a todo instante.

Foi gratificante percebê-lo como humano, como eu, possuidor da mesma centelha de vida e sentimentos que se diferenciam, contudo, na experiência, no existir.

Este trabalho mostrou que, para aqueles homens, este vivenciar se decodificava em três momentos: transformação de sentimentos, percepção de seu papel e acão, configurando como tema central deste estudo BUSCANDO UMA CHANCE PARA O FILHO VIR A SER, que contempla o sentir, o perceber e o agir do pai que vivencia a internação do filho na UTIP, a procura de um existir com plenitude, com oportunidades, chances e igualdade para o filho. Um real ser-aí-com.os-outros.

\section{DISCUSSÃO}

A discussão entre este e outros estudos reveste-se de fundamental importância para a ampliação dos resultados encontrados.

NAKANO; SHIMO (1995) assim como NÉRICI (1972) referem-se ao pai como símbolo de força, proteção e ação, bem como sendo o responsável pelo bem-estar de seu núcleo familiar vindo ao encontro das percepções identificadas no tema Percebendo-se como tomador de decisões, deste estudo.

O papel do homem como apoiador das necessidades maternas de segurança física e econômica, levantadas por DICKSTEIN (1984) são identificados nas falas e contempladas no sub-tema Percebendo-se como apoio para a esposa.

BOUSSO (1992) ressalta que a menor presença do pai na UTI estaria limitada a situação sócioeconômica do casal, não podendo abster-se do mito de provedor, não se permitindo faltar ao trabalho, aumentar os gastos com transporte, se adequar aos rígidos horários de visitas, entre outros, sendo dada a preferência para a mãe acompanhar e visitar ao filho, consoantes com os achados deste estudo, identificados nos depoimentos.

Ficou evidenciado nos discursos o medo e preocupação referentes ao tratamento, pois o pai percebe seus riscos e possível agressão ao organismo da criança, como também assinala GOMES (1992), sendo levantada ainda a idéia de que medicações e procedimentos, como relata ANDERS (1991), seriam "fortes" para aquele pequeno ser que está a mercê da tecnologia.

A confiança em Deus aparece no estudo de GOMES (1992), como a crença do sujeito na intervenção Divina, neste momento em que vivencia esta facticidade.

A mesma autora encontra em seu trabalho ponto em comum com o presente estudo onde a UTI é percebida como local que preserva a vida, vendo naquela unidade e equipe um recurso no tratamento do filho e uma chance para a sua recuperação.

Com estas colocações o fenômeno estudado ganha amplitude e profundidade, levando-me à reflexão sobre as interpretações encontradas e sua relação com o cuidar em Enfermagem direcionado ao pai que experencia a internação do filho em UTIP, objetivo ampliado deste estudo.

\section{REFLETINDO SOBRE O ESTUDO}

O desvelamento do fenômeno, objeto deste estudo, foi além da tentativa de compreender ao pai. 
Foi uma possibilidade de reflexão sobre o que penso, no que acredito e o que reproduzo, enquanto enfermeira. Hoje, meu vivenciar a Enfermagem canalizou-se para o ensino, onde percebo-me muito mais como um agente de transformação do que agente transmissor de conceitos.

A família vem ocupando, espaço no cuidar e cada vez mais vejo a importância de contemplá-la de uma forma mais ampla e menos dicotomizada.

Nesse sentido, entender o significado que representam seus integrantes para a criança e para a própria família, parece-me um ponto de partida para o enfermeiro que a assiste e para o enfermeiro que ensina.

Ficou claro para mim que o pai precisa sentirse decidindo, em ação, tornando-se importante, então, abrir-se para compreender aquele pai e o papel do homem no mundo evitando, contudo, generalizações.

Repenso ainda a questão afetiva onde aceito a idéia de que não preenchemos este espaço junto à criança, além de entender o legítimo e legal direito do pai de estar presente, junto a seu filho, questionando-me, ainda, se absorvemos a noção de que não nos é delegada a tutela daquela criança e que esta possui responsáveis legais a quem devemos, no mínimo, explicações.

Explicar é mais que orientar. Explicar implica em justificar, tornar claro e intelegível seus atos ou palavras, enquanto que orientar refere-se a guiar. O pai precisa de explicações para se situar em relação ao seu papel de pai.

É interessante lembrar o quanto a palavra orientação encabeça prescrições e planos de assitência de Enfermagem.

Pude interiorizar que o poder da equipe é sobre o tratamento e não sobre a criança.

Acredito, ainda, que este olhar mais voltado para o pai possa ser iniciado na Graduação levando ao alunor a idéia de que o cuidado integral ao paciente envolve sua família e mostrando-lhe que o binômio pai-filho existe.

Consciente que este estudo, num primeiro momento, revela-se como uma tentativa de também instigar a reflexão, espero que o despertar para estas possibilidades se voltem para a assistência ao Serpai buscando uma chance para o filho vir a ser.

\section{REFERÊNCIAS BIBLIOGRÁFICAS}

ANDERS, J.C. Estar com os pais em seu vivenciar a doença do filho: uma perspectiva fenomenológica. Rev.Bras.Enf., v. 44, n. $2 / 3$, p.89-97, 1991
$\mathrm{BACH}$, J. O futuro da família: tendências e perspectivas. São Paulo, Vozes, 1983.

BELLI, M.A.J. Assistência à mãe de RN internado na Uti Neonatal :experiências, expectativas e sugestres manifestadas por maes e enfermeiras. Så Paulo, 1992. 102p. Dissertaçáo (Mestrado) - Escola de Enfermagem, Universidade de São Paulo.

BOUSSO, R.S. Aplicabilidade de um instrumento que avalia o impacto da internação da criança em Uti Pediátrica sobre a familia. São Paulo, 1992. 142 p. Dissertação (Mestrado) - Escola de Enfermagem, Universidade de São Paulo.

CARVALHO, A.S. Metodologia da entrevista: uma abordagem fenomenológica. 2.ed. Rio de Janeiro, Agir, 1991.

CAVALVANTI, R.A.Q.L. Aspectos psicológicos da hospitalização da criança. Enf. Novas Dimens., v. 3, n. 6, p. 347-9, 1977.

CHAVES, C.W.; FABER, L. Effect of an education - orientation program on family membres who visit their significant other in the intensive care unit. Heart Lung, v.16, n.1, p. $92-9$ 1987.

DICKSTEIN, J. O papel do pai. In: FONTES, J.A.S Perinatologia social. São Paulo, Fundo Editorial ByKProcienx, 1984. p.51-2.

FIGUEIRA, M.N.de A. Manifestações verbais e não verbais do comportamento materno durante o primeiro contacto personalizado mãe-filho. São Paulo, 1981.60p. Dissertação (Mestrado) - Escola de Enfermagem, Universidade de São Paulo.

FISER, D.H. et al. Service for parental stress reduction in a pediatric INC. Crit.Care Med., v. 12, n. 6, p. 506-7, 1984.

FORGHIERI, Y.C. Psicologia fenomenológica: fundamentos, método e pesquisas. São Paulo, Pioneira, 1993.

GOMES. M.M.F. Ter o filho internado em UTI neonatal : o significado para os pais. Săo Paulo, 1992. 113p. Dissertação (Mestrado) - Escola Paulista de Medicina.

HEIDEGGER, M. Ser e tempo: Parte I. 3.ed. Petrópolis, Vozes, 1989.

MARTINS, J. A ontologia de Heidegger. In: MARTINS, J.; BICUDO, M.A.V. Estudos sobre existencialismo, fenomenologia e educação. São Paulo, Moraes, 1983. p. $33-43$.

NAKANO, A.M. ; SHIMO, A.K.K. Espaço destinado ao homem nos cursos de orientaçáo pré-natal. Femina. v. 23, n. 7 , p. $657-60,1995$.

NÉRICI, I.G. Lar, escola e educação. 3.ed. São Paulo, Atlas, 1972.

ROTHSTEIN, P. Tensão psicológica em família de crianças que estão em um centro de tratamento pediátrico intensivo Clin.Pedriatr.Am.Norte, v. 27, n. 3, p. 631-8, 1980

SILVA, M.A.D. Quem ama não adoece. 3 ed. São Paulo, Best Seller, 1994.p 302-6.

THIS, B. O pai: atos de nascimento. Porto Alegre, Artes Médicas, 1987. 